\title{
A SEMÂNTICA DOS NOMES PRÓPRIOS NUMA ABORDAGEM METALINGUÍSTICA
}

\author{
THE SEMANTICS OF PROPER NAMES IN A METALINGUISTIC APPROACH
}

Josailton Fernandes de Mendonça*

\section{RESUMO}

Este artigo faz a defesa de uma abordagem metalinguística da semântica dos nomes próprios. Nessa perspectiva, procura estabelecer que o significado ou valor semântico dos nomes próprios é dado por uma descrição metalinguística "O portador de 'N'”, prefixando à descrição a cláusula "Atual", tal que a descrição "O atual portador de 'N"' unifica todos os usos do nome próprio para fazer referência singular. Considerando que essa descrição é a expressão da única regra linguística que caracteriza o nome próprio como expressão referencial de largo escopo, procuramos demonstrar que essa descrição manifesta o sentido em que o nome próprio é um designador rígido de jure.

PALAVRAS CHAVE: Metalinguística. Nomes próprios. Semântica. Referente. Designador rígido.

\section{ABSTRACT}

The article makes the defense of a metalinguistic approach to the semantics of proper names. In this perspective, seeks to establish that the semantic meaning or value of proper names is given by a metalinguistic description "The bearer of ' $\mathrm{N}$ "' prefixed to the description the "Actual" clause, such that the description "The actual bearer of' $\mathrm{N}^{\prime \prime}$ unifies all uses of the proper name to make singular reference. Considering that this description is the expression of the unique linguistic rule that characterizes the proper name as a reference expression of wide scope, try to show that this description expresses the sense that the name is a rigid designator de jure.

KEY WORDS: Metalinguistic. Proper nouns. Semantics. Referent. Rigid designator.

\footnotetext{
* Doutor em Filosofia pela Universidade Federal do Ceará -UFC. Professor do Departamento do Filosofia da Universidade do Estado do Rio Grande do Norte-UERN. josailtonf@gmail.com
} 


\section{INTRODUÇÃO}

Neste artigo proponho uma variante da abordagem metalinguística para o significado dos nomes próprios. Um nome próprio denota a classe de todos aqueles indivíduos para os quais o nome tem sido dado; em outras palavras, um nome próprio aponta para uma propriedade geral - também designada como propriedade sortal - que qualifica o nome próprio como expressão de um sistema linguístico. Essa propriedade, que está inserida no quadro das análises da semântica dos nomes próprios desenvolvidas nos últimos anos por Schiffer (1978), Bach (1981), Castañeda (1989), Katz (1994), Recanati (1997), Loar (2006) e outros, qualifica esse termo para ser aplicado significativamente a qualquer número de objetos e é literalmente expresso pela descrição "O atual portador de 'N"'.

$\mathrm{O}$ artigo se encontra deste modo configurado: apresento primeiramente a abordagem metalinguística no que considero suas principais versões (seção 2); depois, examino o problema da referência nessa abordagem (seção 3). Finalmente, sustento, contra as versões da abordagem metalinguística desenvolvidas nos últimos anos, uma variante que é compatível com a concepção dos nomes próprios como designadores rígidos de jure (seção 4).

\section{A ABORDAGEM METALINGUÍSTICA}

Examino nesta seção o tratamento metalinguístico do valor ou conteúdo semântico dos nomes próprios. Para esse fim, apresento as versões mais discutidas na literatura, e por isso mesmo, tomadas aqui como as caracterizadoras da abordagem.

O desenvolvimento da teoria milliana da referência, promovida por Salmon (1982), Kaplan (1989), Putnam (1996), Donnellan (1998), Soames (2002) e outros, suscitou um debate profícuo em torno de determinadas questões relativas ao comportamento semântico das expressões da linguagem, tais como indexicais, demonstrativos, descrições definidas e, sobretudo, nomes próprios. É no quadro dessa discussão que compreendo a abordagem metalinguística da semântica dos nomes próprios.

A origem desse modo de tratar a semântica dessas expressões remete a um aspecto do descritivismo de Russell (1905). De acordo com ele "nomes abreviam descrições" e descrições não nomeiam ou designam coisas, os enunciados que as envolvem têm estrutura lógica que é diferente de sua estrutura gramatical. Por exemplo, o enunciado "O $\phi$ é G" é 
capturada pela forma lógica da proposição $(\exists x)\left(\left(\phi_{x} \&(y)\left(\phi_{y} \rightarrow y=x\right) \& G_{x}\right)\right.$. Nessa situação, enunciados envolvendo descrições da coisa, na posição de sujeito, são decomponíveis em funções proposicionais que expressam propriedades das coisas e não têm a função de nomear que Frege (2009) afirma ter.

Se essa ideia é correta, o problema da referência dos nomes próprios se transforma no problema da referência das descrições definidas que, por sua vez, destituída dessa função referencial, apenas enuncia as propriedades exemplificadas ou não pelos objetos.

A abordagem metalinguística é uma resposta possível ao referencialismo, ao mesmo tempo não deixa de ser uma nova leitura de certos aspectos da teoria descritivista para os nomes próprios. Talvez, por isso mesmo, e face às progressivas retificações da teoria milliana da referência, a explicação para o comportamento semântico dos nomes próprios, sob a ótica do tratamento metalinguístico, apesar de correta - ao menos é o que aqui defendemos - tenha sido sujeita a contínuas rejeições, constituindo-se numa tese minoritária na discussão.

Em linhas gerais, é proposto que o significado do nome próprio é estabelecido por uma relação entre este termo e uma descrição que a ele se reporta. Nesse sentido estrito, penso que podemos compreender que o nome próprio abrevia aquela descrição definida. Trata-se, portanto de uma relação em que um nome próprio é objeto de análise em outra expressão linguística que o menciona. Temos assim caracterizado esse tratamento como metalinguístico.

Vigora em apoio a essa abordagem a ideia de que o valor semântico do nome é a regra linguística representada pela descrição definida que menciona o nome e que constitui o seu conteúdo léxico fundamental. Em resumo, um falante $\mathrm{S}$ refere-se a um particular $\mathrm{x}$, ao proferir $\mathrm{N}$, antes de tudo porque o nome próprio $\mathrm{N}$ tem um valor semântico nos termos da regra linguística que explica o seu poder referencial.

A descrição constituinte do conteúdo léxico do nome varia conforme as especificidades aduzidas para a abordagem. Por exemplo, para Loar (2006, p. 512), “[...] o significado convencional de um nome $\mathrm{N}$ em certo grupo de falantes [...] é o mesmo que o significado convencional da descrição definida 'A coisa ou a pessoa chamada N"'; para Bach (1994), o nome N significa "o portador de 'N"'; para Katz (1994), o sentido de um nome próprio N tem a forma "a coisa a qual é o portador de 'N"”; para Kneale (1962), o nome N significa "O indivíduo chamado ' $\mathrm{N}$ '”,

Mas, apesar de todas as abordagens metalinguísticas explicarem o significado dos nomes próprios, em termos desse significado literal, elas diferem entre si quanto ao entendimento da descrição que funciona como significado literal. Kneale (1962), por exemplo, sugere com a 
descrição "o indivíduo chamado 'N"" uma relação entre o nome e uma propriedade real do portador, tal que somente essa propriedade é capaz de satisfazer à exigência fregiana de determinação de referência, embora não seja informativa. Para Loar (2006), a relação não envolve a rigor a existência de propriedades reais, mas uma regra de uso causalmente fixada, que ele formula em termos de "ser chamado N": x é o referente para o uso geral de $\mathrm{N}$ tanto por aqueles que estão na origem do uso referencial de $\mathrm{N}$ como por aqueles que atualmente são os utilizadores potenciais desse uso de $\mathrm{N}$ para se referir a $\mathrm{x}$. São eles que sustentam e garantem o uso referencial de N. Para Bach (1994) aquela descrição é semanticamente equivalente ao nome mencionado, e invoca apenas uma relação nominal com quem porta o nome. Katz (1994) tem uma ideia semelhante, embora tome a descrição "a coisa que é o portador de N" como constitutiva do sentido do nome. Bach (1994) não invoca a noção de sentido.

Mas o que justifica, em linhas gerais, essa abordagem metalinguística? Inicialmente é importante destacar que ela compartilha da pressuposição básica de toda teoria do significado: o significado de uma expressão da linguagem não é um fato bruto. Por exemplo, não é um fato bruto que a palavra "cavalo" signifique cavalo, nem que a palavra "proton" signifique próton. A questão, portanto, é: que fatos dão a uma expressão da linguagem o seu valor semântico? No caso dos nomes próprios, que fatos fazem com que um nome próprio particular, usado por um falante num determinado contexto, tenha o valor semântico que tem? Há os que respondem asseverando que os objetos, propriedades e relações do mundo determinam o valor semântico das expressões. E há os que defendem que as expressões da linguagem têm seu valor semântico alicerçado no pensamento, isto é, as coisas que pensamos determinam o significado das expressões. A abordagem metalinguística dirige-se ao problema do valor semântico dos nomes próprios afirmando que o significado dos nomes próprios decorre de uma regra linguística. E, como parte de um sistema linguístico, nomes próprios são, como diz Castañeda (1989, p. 37), "variáveis sortais”. O que significa dizer que um nome próprio denota simplesmente a classe de todos aqueles indivíduos para os quais o nome tem sido dado; em outras palavras, um nome próprio aponta para uma propriedade geral da forma "ser chamado tal e tal", ou "o portador de N".

Acredito que é preciso ainda explorar as possibilidades que essa visão metalinguística oferece à explicitação dos aspectos pragmáticos e semânticos dos nomes próprios, tais como o problema da referência singular e da correferência, o fato de um número massivo de 
indivíduos do mundo poder partilhar o mesmo ou diferentes nomes e explicar como enunciados contendo nomes próprios envolvem referência singular.

Nesse sentido, compreendo que os nomes próprios, como parte de um sistema linguístico, podem aplicar-se a qualquer número de indivíduos; a classe dos indivíduos denotados pelo nome instancia ou exemplifica a propriedade "o portador de ' $\mathrm{N}$ " que invoca uma relação nominal entre o nome e o seu portador e não transmite qualquer informação acerca dele, exceto que é o portador do nome. Nesse caso, a única relação que se pode fixar entre o nome e a propriedade descrita "o portador de N" é intralinguística.

Nessa condição, a propriedade transmite o valor semântico do nome citado. Consideremos, por exemplo, as frases (1) a (3) abaixo:

(1) “Cícero" tem seis letras.

(2) "Incipiente" é um adjetivo.

(3) "Sócrates" significa "O portador de "Sócrates"”

Em cada caso, o predicado se aplica a um objeto linguístico. Fala acerca da expressão linguística. Em outras palavras, toma as expressões que ocorrem entre aspas nessas frases como mencionadas antes que usadas. No caso que aqui interessa, exemplificado na frase (3), é dito que entre o nome e a descrição que o menciona vigora uma relação de equivalência semântica a qual especifica o valor semântico do nome. Portanto, uma análise do comportamento semântico dos nomes próprios, em termos metalinguísticos, tem por fundamento o seguinte: um nome $\mathrm{N}$ significa literalmente "o portador de ' $\mathrm{N}$ ", isto é, um nome $\mathrm{N}$ abrevia uma propriedade geral da forma "o portador de 'N'".

Isso suscita a seguinte questão: o que podemos saber acerca de Aristóteles ou Einstein em virtude exclusivamente de seus nomes? "nada", exceto quando seu uso é não literal. Mas, sob a perspectiva, do meu modo de ver a tese metalinguística, o uso não literal do nome é uma ocorrência de um ato de fala metafórico. Por exemplo, é possível usar o nome "Einstein" para se referir a Pedro, querendo, com isso qualificá-lo como pessoa muita inteligente em um enunciado como "No exame Pedro revelou-se um Einstein". Nesses casos, o nome transmite alguma informação, no entanto é um equívoco tomar tais usos comunicacionais como constitutivo do valor semântico do nome próprio. Tais usos atendem a um requisito do contexto, e o nome próprio é livre para transmitir qualquer informação ao operar em um enunciado proferido no contexto de um ato de fala. Como parte do sistema linguístico, o que conta como valor semântico do nome próprio é o fato de se constituir na expressão de uma propriedade tipo, que reúne ou unifica, como num arquivo, todos os possíveis usos dos nomes 
segundo o contexto, as crenças e as informações do falante. Nesse sentido, enquanto expressão linguística o nome próprio não é um termo singular, como mencionei, trata-se de "uma variável sortal".

A esse respeito dois pontos precisam ser esclarecidos: o primeiro deles é que essa concepção pressupõe a distinção entre o uso e as regras da linguagem; o segundo é que a análise metalinguística dos nomes próprios não é uma teoria da referência, no sentido de que não tem como objetivo central fornecer resposta à seguinte questão: quais são as condições necessárias e suficientes para que um indivíduo $\mathrm{P}$, através de um nome $\mathrm{N}$, se refira a um objeto $\mathrm{x}$ ?

Com relação ao primeiro ponto, de fato, as regras da linguagem estão situadas no níveltipo, constituídas pelas normas semânticas e sintáticas. Já as características de uso da linguagem estão sujeitas às vicissitudes inerentes ao que é dito num certo contexto por certo falante. São os tokens ou ocorrências linguísticas. A relação entre as regras e o seu uso efetivo no que é dito um problema à parte nesta discussão. De qualquer maneira, é importante ressaltarmos, para os fins pretendidos neste estudo, que a distinção entre regras linguísticas e uso efetivo é fundamental em teoria da comunicação. A ideia de significado natural e significado não natural é decisivo em trabalhos como o de Grice (1975) e Searle (1958); a concepção de que é possível que um enunciado diga mais do que o literalmente expresso encontra respaldo nas motivações cognitivas do falante e no impacto cognitivo sobre o ouvinte, das crenças e desejos que o falante imprime ao que é dito. Sem dúvida, esses resultados, por assim dizer, não podem ser desconsiderados em uma análise semântica, seja dos nomes próprios, seja dos termos gerais.

Assim, chegamos ao segundo ponto, a saber, a concepção metalinguística não é uma teoria da referência. Remetemos a justificativa dessa concepção à seção seguinte.

\section{A REFERÊNCIA DOS NOMES PRÓPRIOS NA TEORIA METALINGUÍSTICA}

Em geral, o que em filosofia da linguagem é chamado de referencialismo é a tese que promove o referente de uma expressão nomeadora, seja um nome próprio, uma descrição definida, um demonstrativo ou ainda um indexical, à condição de constituinte fundamental do seu conteúdo semântico. Ocorre que essa tese é uma resposta a um problema fundamental em filosofia da linguagem, a saber, como uma expressão linguística nos conecta a algo no mundo? Em particular, como explicar que o nome próprio nos conecte a algo no mundo? A 
questão e a sua resposta traduzida no referencialismo, com relação aos nomes próprios, não deixa de ser embaraçosa, pois cria uma série de outras questões igualmente complexas como, por exemplo, o problema do significado dos nomes próprios sem referentes, os chamados nomes vazios e o problema de definir o caráter proposicional de enunciados que contêm essas expressões. Alguns teóricos, como por exemplo, Strawson (1950) e Kripke (1980), assumem que o referir é um fenômeno particular extralinguístico e o referente é o que está fora da rede linguística, é o objeto a que o nome próprio está associado na forma de seu conteúdo semântico. Pensamos que o exame da relação entre nomes próprios e objetos por eles nomeados, isto é, a conexão nome-mundo, não pode prescindir da distinção entre essas noções fundamentais.

A princípio compreendemos que referir não é uma peculiaridade dos nomes próprios. É possível fazê-lo com indexicais, figuras, e muitos outros códigos convencionalmente estabelecidos. E em todos esses casos o ponto comum, seguindo aqui Geurts (1997), é que alguma associação é feita entre o nome e o seu portador; logo, referir é uma ação interna do falante, nesse sentido incorpora elementos contextuais e psicológicos. Mas se o ato de referir é extralinguístico, não o pode ser o referente.

Por referente entendemos o interpretante a que o signo, em particular, o nome próprio remete $^{1}$. Consideremos por exemplo o nome "Pelé". Como signo, o nome representa um objeto, não em sua totalidade - talvez nem a mãe de Pelé o conhecesse assim! - mas em relação a um quadro que contém os aspectos perceptuais, as crenças, as atitudes e o contexto do falante que, com o uso do nome, quer indicar a pessoa Pelé. Mas para que o falante cumpra seu objetivo ele deverá conhecer um conjunto de fatos em relação a Pelé - sempre de acordo com um quadro de referência - e tais fatos são representados no signo a partir do qual o falante apreenderá aspectos do objeto. Portanto, um signo (nome próprio) engendra outro signo que interpreta o objeto sob certo modo. É esse signo com base no qual o falante apreende aspectos do objeto que denominamos, na linha de Pierce (1995), interpretante.

Como interpretante, o referente não pode se confundir com o objeto tomado em si mesmo. O objeto fora da rede de signo linguístico não nos é acessível, portanto, trata-se sempre de

\footnotetext{
${ }^{1}$ Adotamos no decorrer desta análise do conceito de referente o conceito pierciano de "interpretante". Com efeito, de acordo com Pierce (1995), "um signo ou representamen, é uma coisa qualquer que está para alguém em lugar de outra coisa qualquer sob um aspecto ou a um título qualquer. Dirige-se a alguém, isto é, cria no espírito desta pessoa um signo equivalente ou talvez um signo mais desenvolvido. A este signo que ele cria dou o nome de interpretante do primeiro signo. Este signo está no lugar de qualquer coisa: do objeto. Está em lugar deste objeto, não sob todos os aspectos, mas em referência a uma espécie de ideia a que por vezes tenho dado o nome de fundamento do representamen" (1995, Collected papers, 2.228)
} 
uma relação entre o signo, o seu interpretante e um conjunto de fatores contextuais e intencionais. Nessas condições, o referente-interpretante de um nome próprio pode existir como coisa/indivíduo real ou concreta, ou simplesmente não existir nessa condição. Quando o referente-interpretante existe como coisa/indivíduo real ou concreta, dizemos que o nome próprio denota, ou ainda que tal referente-interpretante tem a função de denotatum do nome, mas quando o referente-interpretante não existe como coisa/indivíduo real ou concreta, dizemos que o nome próprio designa ou que tal referente tem a função de designatum do nome ${ }^{2}$.

Finalmente, tomo por referência ou referencial precisamente a propriedade léxica do nome próprio, isto é, a regra que permite essa expressão ser usada para referir. Se for assim, o que caracteriza o nome próprio, como signo linguístico que é, é a disposição para referir, dada sua propriedade referencial. Essa propriedade é expressa através da descrição "o portador de 'N'" - adiante, pelas razões que serão aduzidas, acrescentaremos a expressão "atual". Considerando que nem sempre é muito claro o modo como a tese metalinguística explica a relação nome próprio e objeto do mundo e observando que esta relação é fundamental na caracterização semântica do nome próprio, acreditamos que a distinção aludida entre referir, referente e referência, permite à tese metalinguística esclarecer, com maior rigor, a caracterização semântica do nome próprio. Duas consequências tratamos como as mais importantes nessa perspectiva: a primeira é que a condição de possibilidade do ato de referir é a existência da referência como norma linguística, do referente como signo verbal ou linguístico objetivo, autônomo e da coisa referida que se apresenta no signo interpretante. Isso faz do referir uma relação triádica: sujeito falante-referente-referência. A referência, enquanto função do nome próprio representada nos termos da descrição metalinguística “o portador de 'N'”, é exemplificada no ato de referir a um signo interpretante ${ }^{3}$ - denotando ou designando o qual não está fora da esfera linguística. Portanto a referência não se esgota na norma, embora esta seja indicadora da disposição do nome próprio designar ou denotar um referente-

\footnotetext{
${ }^{2}$ Pierce (1995, Collected papers 1538) diz: "Todo signo representa um objeto independente dele mesmo, mas ele só pode ser signo deste objeto na medida em que este objeto tem, ele mesmo, a natureza de um signo, de um pensamento". A distinção a que aludo procura conforma-se a esta assertiva pierciana. Desde que o objeto, por um lado, engendra o signo e por outro este signo é independente do objeto, é possível falar de signos enquanto remetem a objetos reais e concretos e enquanto remetem a objetos inexistentes. Observo que o signo é sempre indicador; engendra o aparecimento do objeto segundo um quadro de referência.

${ }^{3}$ Em consonância com a definição pierciana na nota 1, compreendemos o interpretante como o que produz na mente do intérprete aquilo a partir do qual a interpretação se realiza. Portanto é um fenômeno essencialmente circunscrito à esfera da pragmática.
} 
interpretante. A outra consequência é para o caráter proposicional singular dos enunciados que contêm o nome.

Segundo sua função pragmática, os enunciados são classificados em interrogativos ("João está ai?”), imperativos (“João, apanhe o livro!"), interjectivas (“Ah, se chovesse em Fortaleza!”) e declarativas (“Russell é alto”). Os enunciados declarativos são os únicos que têm valor de verdade. Nosso interesse recai sobre esses enunciados. O interesse particular por esses enunciados decorre de sua estreita ligação com a noção de proposição. Em geral o que faz um enunciado verdadeiro ou falso é a proposição expressa por ele numa dada ocasião. Proposição é o pensamento expresso por um enunciado declarativo com sentido. Enunciados declarativos contendo termos singulares (nomes próprios, demonstrativos e indexicais) transmitem, segundo uma tradição referencialista, uma proposição singular, é o caso das teses sobre nomes próprios de Mill (1979), Kripke (1980), Donnellan (1998) e outros. Enunciados declarativos, contendo descrições definidas na posição de sujeito gramatical, transmitem, de acordo com essa mesma tradição referencialista, proposições gerais, como parece ser o caso de Frege com seu conceito de "modo de apresentação" associado ao sentido do nome próprio, e certamente é o caso de Russell com a tese de que nomes próprios abreviam descrições definidas e a forma lógica de enunciados declarativos singulares são proposições gerais. Os proponentes da abordagem metalinguística são vagos com relação a essa distinção. À primeira vista os enunciados declarativos contendo nomes próprios são proposições gerais, pois o valor semântico do nome próprio é uma descrição metalinguística. Entretanto, a descrição metalinguística não tem conteúdo informacional identificador, logo, parece incapaz de explicar o fenômeno da referência singular.

Entretanto, a meu ver, a partir das distinções aludidas acima entre referir, referente e referência, é admissível compreender a referência singular como um fenômeno pragmático que ocorre no interior de uma estrutura sintático-semântica. Nessas condições, quando um falante A profere o enunciado "Aristóteles morreu em Calcis", a capacidade referencial do nome "Aristóteles" é assegurada pela regra semântica que associa ao nome "Aristóteles" a descrição "O portador do nome 'Aristóteles'”, como o seu significado léxico; a unicidade do referente-interpretante está assegurada pelo contexto e a intenção de referir do falante; e, finalmente, o falante nesse percurso possui certa inclinação, tendência ou disposição de associar ao nome próprio uma descrição definida cuja função é apresentar ou explicitar, designando ou denotando algo, que funciona sempre como o referente-interpretante. Nessas condições, nomes próprios em enunciados declarativos que os contêm transmitem proposições 
singulares e estas resultam de um fenômeno pragmático. Portanto, é na esfera de uso da linguagem que cada nome próprio remete a um denotatum ou a um designatum, isto é, é nessa esfera que o nome nos conecta a algo no mundo. Assim, a função referencial singular do nome próprio é assegurada por um conjunto de fatores - contexto, a intenção de referir do falante, suas crenças e percepções - que estão na base da associação que é feita entre o nome e o objeto, apresentado como signo interpretante.

Penso assegurar assim um importante desiderato, a saber, o fenômeno da referência singular deve considerar por um lado a abertura semântica dos nomes próprios - definido em termos de sua liberdade de aplicar-se sempre a novos indivíduos interpretantes sem com isso constituir uma mudança semântica; por exemplo, quantas Luizas, quantas Marias, etc. existem - e ao mesmo tempo a propriedade geral "o portador de 'N'" que, como a regra semântica fundamental, reúne e justifica a universalidade dessa abertura semântica e o nome próprio como expressão com função referencial singular.

Como indicado anteriormente, os proponentes da tese metalinguística divergem quanto à questão da referência singular. Loar (2006, p. 508), por exemplo, argumenta que para explicar a função semântica de um termo singular não é exigida a função de referir. Realmente, um proferimento pode ser da espécie referencial, ainda que falhe em referir, tal como parece ser o caso dos chamados nomes próprios vazios. De qualquer modo penso que nomes próprios, vazios ou cheios, preservam sua função referencial singular, à medida que cada uso de um nome próprio num enunciado representa um exercício, pelo falante, de um mecanismo de referência singular, ou como diz Castañeda (1988), tal uso seleciona uma fatia do conjunto dos indivíduos portadores daquele nome. Nessas condições o nome é um mecanismo linguístico formal - expressão tipo - dotado de uma função referencial que se efetiva pelas suas ocorrências.

Havia introduzido esta discussão a respeito da função referencial dos nomes próprios a partir da caracterização do referencialismo. Procurava, assim, apresentar no quadro da abordagem metalinguística uma resposta à seguinte questão: como cada uso de um nome $\mathrm{N}$ por um falante que tem $\mathrm{N}$ em seu sistema linguístico pode nos dar como referente (denotatum ou designatum) um indivíduo que é uma parcela do conjunto dos indivíduos possíveis que associamos a N? A questão é crucial à semântica dos nomes próprios, sobretudo, porque remete ao tema da rigidez semântica dessas expressões. Passamos então a examinar uma vertente desse problema, a saber, é possível conciliar o tratamento metalinguístico com a tese 
da rigidez dos nomes próprios? Procuraremos demonstrar que, sob determinadas condições, a noção de rigidez não é inconciliável com a abordagem analisada.

\section{A ABORDAGEM METALINGUÍSTICA E A TESE DA RIGIDEZ DE JURE DOS NOMES PRÓPRIOS}

A noção de rigidez surgiu com o desenvolvimento da semântica da lógica modal quantificada (LMQ) para explicar o comportamento das variáveis dessa lógica. Pontualmente, a noção de rigidez encontra-se conectada a uma interpretação objetual da LMQ em que o âmbito do operador modal e quantificador são relativos a objeto antes que a frases.

De modo geral, a lógica modal é uma lógica ortodoxa, no sentido de preservar noções semânticas importantes da lógica formal, tais como, os valores de verdade - verdadeiro e falso - satisfatibilidade, interpretação e os princípios da lógica clássica (não contradição, terceiro excluído, identidade e o princípio da substituição) ${ }^{4}$. Contudo, o traço mais saliente da lógica das modalidades diz respeito ao fato de os valores de verdade dos enunciados modais serem determinados de acordo com os "fatos" existentes nos vários mundos possíveis. Portanto, temos duas noções semânticas fundamentais: a de valor de verdade e a de extensão ou denotação, ambos relativos a mundos possíveis e sobre as quais emerge a noção de designador rígido. ${ }^{5}$ Examinemos, por exemplo, as seguintes frases:

(4) Possivelmente alguém é Deus.

(5) Há um ser o qual possivelmente é Deus.

De acordo com o enunciado (5) o âmbito do operador modal e do quantificador é relativo ao enunciado "alguém é Deus", isso quer dizer que essa frase é possivelmente verdadeira, ou seja, no mundo atual existe uma pessoa que tem a propriedade de ser Deus em algum mundo possível acessível. E se é verdade, para o mundo atual, que alguém é Deus em algum mundo, então este alguém deve existir no mundo atual. É a interpretação não objetual ou conceitual da LMQ. Mas (4) requer, para o mundo atual, que haja algum mundo no qual alguém seja Deus;

\footnotetext{
4 A esse respeito lembramos aqui o seguinte: a própria possibilidade de quantificar enunciados modais é questionada, conforme a tese da inadequação do princípio da substituição nos enunciados modais que, segundo Quine (1976), são referencialmente opacos. No entanto, a tese quiniana não tem a última palavra. Trabalhos como os de Carnap (1956), Kripke (1963), Barcan (1993), e outros, buscarem salvar a significatividade da quantificação dos enunciados modais num esforço que se justifica pelo fato de qualquer sistema de lógica modal sem quantificação só é relevante se considerado como base para incluir a quantificação.

${ }^{5}$ Esta noção, contudo, está longe de ser inocente. Embora seja uma noção técnica, ela enseja inúmeras polêmicas filosóficas, sobretudo, quando se combina modalidade e quantificação. De fato, a lógica modal quantificada envolve uma interpretação dos operadores, que remete a um compromisso com a existência de propriedades essenciais para o objeto.
} 
ou seja, a condição para alguém existir e ser Deus no mundo atual é que, primeiramente ele exista nesta condição em algum outro mundo, ou seja, a modalidade é atribuída a um indivíduo. É a interpretação objetual da LMQ.

A interpretação objetual, se por um lado é desejável para preservar o princípio da substituição, tanto quanto a concepção de satisfação na quantificação da lógica modal é, por outro lado, imprescindível para assegurar que as variáveis e termos dessa lógica sejam rígidos. E essa rigidez se justifica, segundo Stanley (1997), por razões de ordem técnica: permitir um tratamento uniforme da classe dos termos, pois se assim for as variáveis não livres podem ser tratadas, na semântica, como variáveis cuja interpretação não depende da atribuição; se consentirmos designações não rígidas devemos restringir a regra da instanciação universal a designadores rígidos, o que é bastante desagradável. Finalmente, conclui Stanley (1997, p. $562)$,

[...] não há compromisso com a tese de que todos os termos na linguagem comum são rígidos. Termos rígidos apenas desempenham o papel, nesta fase, de desejáveis ferramentas semânticas formais, o que nos permitirá uma melhor compreensão da noção objectual de satisfação, bem como uma explicação sobre a validade da substituição clássica.

Contudo se compreendermos a LMQ como uma representação do discurso modal na linguagem comum, a noção de rigidez dos termos é problemática, em particular, teremos o problema da demonstração filosófico-semântica da noção de rigidez. Essa demonstração permitiria à linguagem comum apoiar a semântica da quantificação da lógica modal. Caso contrário, a noção de rigidez seria um artifício ad hoc para estruturar a quantificação de lógica modal.

O trabalho desenvolvido por Kripke, sobretudo em Naming and Necessity (1980), tem como um dos seus propósitos chamar a atenção para como interpretamos normalmente enunciados modais com a ocorrência de nomes próprios. De fato, isso parece suficiente para convencer o leitor da rigidez dos nomes próprios. E, assim, o conteúdo semântico dessas expressões não pode ser dado por descrições definidas.

De acordo com Kripke (1980) a rigidez está ligada às condições de verdade dos enunciados em que comparece o termo rígido. Assim, dizer que um designador é rígido é dizer que há um indivíduo tal que, em todas as situações contrafactuais, as condições da verdade do enunciado em que comparece aquele designador envolvem aquele indivíduo. Tomemos, por exemplo, o nome "Einstein", para designar a pessoa de Einstein. Na condição 
de designador rígido, esse nome designa em todo mundo possível a pessoa designada por "Einstein" no mundo atual.

Em Naming and Necessity (1980, p. 26, nota 21; p. 112 nota 56) há ainda uma distinção entre rigidez de jure e rigidez de facto. Uma expressão é um designador rígido de jure de um objeto apenas no caso da regra semântica da linguagem ligá-lo, sem mediação, àquele objeto. O conteúdo intuitivo da rigidez de jure ${ }^{6}$ apoia-se na ideia de que a regra semântica toma a forma de uma estipulação que denota certo objeto. Na rigidez de facto, uma descrição que expressa um atributo essencial do designado se conserva, em outros mundos possíveis, como condição para a existência, nesses mundos, do objeto referido pela descrição. Por exemplo, a descrição "a raiz cúbica de 27 ” designa, em todas as situações contrafactuais, o número três: 3 é em todos os mundos possíveis raiz cúbica de 27 . A rigidez de facto apoia-se na metafísica ou numa tese essencialista. Com efeito, descrições definidas podem ser rígidas (de facto), mas não rígidas de jure.

Ocorre que é através das descrições definidas que os nomes próprios estão ligados à realidade extralinguística, ao menos de acordo com o modelo descritivista de referência. Este modelo responde a seguinte questão: em virtude do que um nome " $\mathrm{N}$ " tem o referente que tem? Assim, um nome próprio como “Aristóteles” denota a pessoa Aristóteles porque está associado a um conjunto de descrições satisfeitas unicamente por Aristóteles. Aquilo a que a noção de rigidez se contrapõe, no entanto, é o modelo descritivista de conteúdo dos nomes próprios. Por outro lado o que define o descritivismo de conteúdo é a defesa da tese segundo a qual as descrições que explicam porque " $\mathrm{N}$ " tem o referente que tem também determinam o conteúdo ou valor semântico de "N".

O exemplo da barra de um metro em Paris dada por Kripke (1980) explicita essa questão. Kripke afirma que há diferença intuitiva entre a expressão "Um metro" e a expressão "O comprimento de B em to". A primeira expressão é um designador rígido, enquanto a outra, não. É claro, em algumas situações, o comprimento de B pode não ser de um metro. Mas isso não inviabiliza o uso dessa expressão descritiva para fixar a referência de "Um metro", pois não estamos usando esta descrição para firmar o conteúdo semântico de "Um metro"; antes estipulando que "Um metro" deverá ser definido em termos de "O comprimento de B em $\mathrm{t}_{0}$ ",

\footnotetext{
${ }^{6}$ Kripke ressalta o caráter intuitivo da rigidez de jure em vários momentos em Naming and Necessity: "Uma das teses intuitivas que sustentarei nestas falas é que os nomes são designadores rígidos" (1980, p. 48); "Minha observação mais importante é, então, que temos uma intuição direta da rigidez dos nomes, a qual é posta de manifesto em nossa compreensão das condições de verdade das frases particulares" (1980, p.19), em (1980, p. 51-52) ele destaca exatamente a intuição como evidência em favor da rigidez dos nomes. No prefácio ele já argumentava que nossas intuições corroboram a tese de que os nomes próprios são rígidos.
} 
em todas as situações contrafactuais. Isto é, estipulamos que a expressão "Um metro" designará rigidamente uma medida de comprimento que de fato é o comprimento de $\mathrm{B}$ em $\mathrm{t}_{0}$. Coisa análoga explicaria então a rigidez dos nomes próprios. Consideremos por exemplo alguém que deseje introduzir o signo "Colombo" dizendo algo como: "designarei por "Colombo" o homem que descobriu a América, quer esteja falando do mundo atual ou de qualquer circunstância contrafactual”. Introduzido dessa forma na linguagem, a expressão "Colombo" individualizará em toda situação contrafactual exatamente aquele que no mundo atual é o homem que descobriu a América. Em outras palavras "Colombo" é um designador rígido.

Mas, quem assim procedeu tinha uma intuição fundamental acerca dos nomes próprios: essas expressões têm a propriedade semântica de individualizar o seu portador. Isto é, na origem da rigidez designativa do nome "Colombo" encontra-se uma propriedade semântica. Diz-se então que "Colombo" é um designador rígido de jure.

Kripke toma a rigidez como uma propriedade dos nomes não como um fenômeno relativo ao seu uso pelos falantes. Ao menos é o que transparece quando ele diz (1980, p. 11), por exemplo, "eventualmente cheguei a perceber que [...] de fato pode-se sustentar a intuição geral de que os nomes da linguagem natural são designadores rígidos [...]”. Depois na famosa nota 21 do prefácio de Naming and necessity essa ideia é ressaltada ao caracterizar os nomes próprios como rígidos de jure. Mas nessas condições, como explicar a questão dos múltiplos portadores do mesmo nome? Kripke (1980, p. 13) propõe o seguinte:

\footnotetext{
Para a linguagem, como a temos, poderíamos falar dos nomes como se tivessem um referente único, desde que adotássemos uma terminologia [...] de acordo com a qual o uso dos sons foneticamente iguais para nomear objetos distintos conta como nomes diferentes. Certamente esta terminologia não está de acordo com muitos dos usos comuns, entretanto, pode ter muitas vantagens que a recomendam para propósitos teóricos. (Tradução nossa).
}

Assim, dentro dessa concepção cada nome é único em sua individualização, isto é, não há dois nomes iguais, até porque são cadeias causais históricas de referências completamente distintas. Por exemplo, o nome "Mateus" para designar, no mundo atual, com respeito a todas as situações contrafactuais, "O homem que escreveu o primeiro evangelho" é completamente diferente do nome "Mateus" para designar, no mundo atual, e com respeito a todos os mundos possíveis “O diretor da fábrica em que eu trabalho". Embora foneticamente iguais, são 
segundo Kripke, nomes distintos, na medida em que apoiam-se em cadeias causais históricas completamente diferentes.

Entretanto, há vários problemas com essa proposta. Katz identifica algumas consequências implausíveis. Por exemplo, um falante chamado "Pedro" que dissesse para alguém também chamado "Pedro", "Olha, temos o mesmo nome!" estaria dizendo algo literalmente falso; se Kripke estiver certo, é redundante acrescentar a expressão "Junior" para o nome do filho que partilha do nome do pai; os nomes que identificam pessoas da mesma família como, por exemplo, "Sena", "Barbosa", nesta proposta de Kripke, perdem essa importante função.

Contudo, parece-me que a proposta de Kripke, haja vista assegurar a unicidade do designatum, salva a singularidade de proposições em que aparecem os nomes próprios e estabelece um "modelo de conteúdo oficial" dessas expressões. Isso porque enquanto nomes próprios contribuem com o objeto para o conteúdo semântico dos enunciados em que comparecem, descrições definidas contribuem com o modo de apresentação ou com a condição que deve ser satisfeita pelo objeto. Nesse aspecto cada nome próprio é único em sua função referencial individualizante.

Conforme já ressaltei, rigidez dos nomes próprios parece asseverar que todo modelo descritivo do conteúdo dessas expressões é falso. Contudo, rigidez dos nomes próprios não parece refutar outras análises descritivistas de conteúdo como é o caso dos indexicais, das descrições que expressam conceitos gerais, como por exemplo, "o menor número primo", "o metal de número atômico 79", e das descrições definidas prefixadas pela palavra "atual".

No caso dos indexicais e demonstrativos as regras da linguagem associadas ao uso dessas expressões determinam as condições sob as quais elas referem. As descrições a elas associadas expressam as regras que asseguram o uso referencial singular dessas expressões. A expressão "Eu", por exemplo, define-se como "O falante que diz 'Eu"”; o pronome demonstrativo "Você" denota aquele a quem se refere num dado contexto; "Agora" refere um tempo, em um contexto. Descrições expressivas de conceitos gerais podem ser compatíveis com a análise dos conteúdos dos termos gerais. É o que Kripke denomina de designadores rígidos de facto. E finalmente as descrições prefixadas pela expressão "Atual”. Ocorre aqui o seguinte: a análise do conteúdo dos nomes próprios em termos de descrições definidas prefixadas pela palavra "Atual” não parece contrariar a tese da rigidez semântica daquela expressão. Por quê? Há uma característica dos indexicais e demonstrativos compartilhada pela expressão "Atual” que torna possível sustentar que esta palavra é um indexical. Nos indexicais e demonstrativos o contexto determina certo parâmetro de aplicação da regra 
linguística associada à expressão, por exemplo, se chego ao departamento de filosofia e encontro um cartaz na porta com a seguinte informação "Hoje o secretário não vem", o contexto é fundamental na determinação do significado da expressão "hoje" e, portanto, da compreensão da frase pelo ouvinte-leitor. Se é assim parece natural incluir a palavra "Atual" na lista dos indexicais uma vez que no contexto da semântica dos mundos possíveis "Atual" indica o mundo como contexto. Logo, a descrição definida "O atual F" denota com respeito ao contexto de todo mundo possível o mesmo objeto, nomeadamente, o único $\mathrm{F}$ do mundo atual. Sob esta análise, descrições pré-fixadas pela palavra "atual” são rígidas.

Essas condições parecem permitir concluir pela análise do valor semântico dos nomes próprios em termos de descrições definidas pré-fixadas pela palavra "Atual”, sem prejuízo da tese da rigidez daquelas expressões. Entretanto, a nosso ver existem dois problemas profundamente relacionados com essa proposta: o primeiro chamaremos de "problema da mediação semântica"; e o segundo, a concepção dos nomes próprios como designadores rígidos de jure. Analisaremos ambas as dificuldades conjuntamente.

Um designador rígido de jure designa sem a mediação de uma propriedade do objeto ou descrição, conforme é o caso com os termos gerais - "Ouro", "Leão", e outros. Ao afirmar que nomes próprios são rígidos de jure é assumida a concepção, de acordo com a qual a maneira como é determinada a singularidade referencial dessas expressões escapa a qualquer forma de essencialismo. De fato, segundo a tese da rigidez semântica dos nomes próprios, sua singularidade referencial decorre estritamente das regras linguísticas na forma de uma estipulação que remete um nome próprio $\mathrm{N}$ a certo objeto. Kripke reconhece assim que nomes próprios não têm conteúdo descritivo.

Mas descrições definidas "atualizadas" não são rígidas de jure, isto é, uma descrição como "O atual autor de Word and Object" designa Quine através da mediação de um conceito. Nessa condição, desde que nomes próprios são rígidos de jure, a análise do seu significado não poderia ocorrer em termos de descrições "atualizadas". Descrições definidas "atualizadas" permitiriam justificar que nomes são expressões rígidas, mas não rígidas de jure.

Por esse ângulo, é possível afirmar que os nomes próprios designam o que designam rigidamente via mediação. Um exemplo nessa perspectiva é dado por Evans (1985). Suponha que desejássemos saber o que teria acontecido se o inventor do zíper tivesse morrido ao nascer. Não sabemos quem inventou o zíper. Introduzimos o nome "Júlio" pela seguinte estipulação fixadora da referência: 


\section{Referente ("Júlio") = O inventor do zíper}

Podemos então especular a respeito do que aconteceria se Júlio tivesse morrido ao nascer e o zíper não tivesse sido inventado. Supondo que "Júlio" é um designador rígido temos o seguinte:

i. Júlio pode não ter sido Júlio

ii. Júlio pode não ter sido o inventor do zíper

Claramente (i) é falso, mas (ii) é verdadeiro. Nessa condição "Júlio" designa o que designa através da mediação, e, portanto, não é um designador rígido de jure.

É claro que, sob uma análise descritivista, nenhum nome próprio é um designador rígido. Por outro lado, a questão da rigidez parece ser simplesmente independente da questão do conteúdo descritivo dos nomes, pois é perfeitamente plausível manter a tese do conteúdo descritivo dos nomes e sua rigidez semântica, como bem o demonstram as descrições definidas contendo expressões indexicais, em particular, descrições definidas "atualizadas". Além do mais, Kripke nunca argumentou que suas considerações modais refutavam toda análise descritivista do conteúdo dos nomes próprios. Assim, acreditamos que seja possível estabelecer a rigidez de jure dos nomes próprios apoiado no seu significado metalinguístico. Conforme indicamos anteriormente, nomes próprios, como parte do sistema linguístico, podem se aplicar a qualquer número de objetos. Seu valor semântico decorre de uma propriedade sortal "o portador de ' $\mathrm{N}$ ". Essa propriedade é meramente reflexiva e garante que nomes próprios são expressões designadoras usadas para a referência singular nos processos comunicacionais. Ao prefixarmos a cláusula "atual" à descrição metalinguística "o portador de 'N'", especificamos, com respeito ao contexto de todo mundo possível, os mesmos objetos, nomeadamente, "o portador de "N"' do mundo atual. Com isso, pensamos assegurar através da regra sintático-semântica que qualifica "N" para o uso referencial singular a unicidade de todos os possíveis usos de "N". Nestas condições nomes próprios não deixam de ser designadores rígidos de jure.

\section{CONCLUSÃO}

Ao longo do artigo procuramos desenvolver uma argumentação em defesa da abordagem metalinguística acerca da semântica dos nomes próprios. Nessa perspectiva, ressaltamos os aspectos que justificam o valor dessa abordagem diante da alternativa referencialista, sobretudo de Kripke. Um desses aspectos é que o tratamento metalinguístico permite tomar os 
nomes próprios como vocábulos da língua e não meras marcas identificadoras. Por esse ponto de vista, buscamos explicitar uma noção de referência que fosse pertinente com o tratamento metalinguístico. Finalmente, face às criticas de muitos de seus proponentes à noção de designador rígido, argumentamos em favor de um tratamento metalinguístico da semântica dos nomes próprios que, a nosso ver, é condizente com a tese da rigidez dessas expressões. Assim, desde que essa é uma tese central na justificativa semântico-filosófica da quantificação da lógica modal, sugerimos então compreender a descrição metalinguística "o portador de 'N"” pré-fixando à descrição a cláusula "Atual", tal que a descrição "o atual portador de 'N"” encerra todo o significado ou valor semântico dos nomes próprios. Como esta descrição é a expressão da única regra linguística que caracteriza o nome próprio como expressão referencial de largo escopo, entendemos que essa descrição manifesta o sentido em que o nome próprio é um designador rígido de jure.

\section{REFERÊNCIAS}

BACH, Kent. What's in a name? Australasian Journal of philosophy, v. 59, n. 4, p. 371 386. 1981.

BACH, Kent. Descriptivism Distilled. Unpublished manuscript. 1994. Disponível em: <http://online.sfsu.edu/ kbach/oldies/descriptivism.html>. Acesso em: 15 set. 2015.

BARCAN, Ruth Marcus. Modalities philosophical essays. New York, Oxford: Oxford university press, 1993.

CASTAÑEDA, Hector-Neri. Thinking, language and experience. Minneapolis, USA. University of Minnesota press, 1988.

CARNAP, Rodolf. Meaning and necessity: a study in semantics and modal logic. Chicago: The university of Chicago press, 1956.

DONNELLAN, Keith. Reference and definite. In: OSTERTAG, Gary. Definite descriptions: a reader. Massachusetts: Massachusetts Institute of Technology, 1998, p. 173-193.

EVANS, Gareth. The varieties of reference. Oxford: Oxford University Press, 1982.

FREGE, Gottlob. Sobre o sentido e a referência. In: Lógica e filosofia da linguagem. Tradução Paulo Alcoforado. 2. ed. São Paulo. Editora Universidade de São Paulo, 2009, p. 129-158.

GEACH, Peter. Reference and generality: an examination of some medieval an modern theories. Ithaca: Cornell university press, 1962.

GUERTS, Bart. Good news about the description theory of names. Journal of Semantics, n. 4, v. 14, 1997, p. 319-348. 
GRICE, Herbert Paul. Logic and conversation. In: COLE, Peter; MORGAN, Jerry (Ed.). Sintax and semantics, v. 3. New York: Academic press, 1975.

KAPLAN, David. Demonstratives: an essay on the semantics, logic, metaphysics, and epistemology of demonstratives and other indexicals. In: ALMOG, Joseph; PERRY, John; WETTSTEIN, Howard. Themes from Kaplan. New York: Oxford University Press, 1989, p. 481-579.

KATZ, Jerrold. Names Without Bearers. Philosophical Review, n. 103. v. 1: p. 1-39, 1994.

KNEALE, William. Modality De Dicto and De Re. In: NAGEL, Ernest; SUPPES, Patrick; TARSKI, Alfred (Ed.). Logic, Methodology, and Philosophy of Science. Stanford: Stanford University Press, p. 622-633, 1962.

KRIPKE, Saul. Semantic considerations on modal logical. Acta philosophica Fennica, n. 16, 1963, p. 83-94.

KRIPKE, Saul. Naming and Necessity. Cambridge: Harvard University Press, 1980.

LOAR, Brian. The semantics of singular terms. In: DAVIDSON, Matthew. On sense and direct reference: readings in the philosophy of language. USA: Mcgraw-Hill, 2006, p. 496516.

MILL, John Stuart. Sistema de lógica dedutiva e indutiva. Tradução Pablo Mariconda. 2. ed. São Paulo: Abril, 1979, p. 89-257. (Os pensadores).

PEIRCE, Charles Sanders. Semiótica: seleção de textos dos collected papers. Tradução Teixeira Coelho Neto. São Paulo. Perspectiva, 1995.

PUTNAM, Hillary. The meaning of 'meaning'. In: PESSIN, Andrew; SANFORD, Golberg. The twin earth chronicles: Twenty years of reflection on Hilary Putnam's. New York, M.E. Sharp, p. 2-52, 1996.

QUINE, Willard Von Orman. Quantifiers and propositional attitudes. In: QUINE, Willard Von Orman. The ways of paradox and other essays. Cambridge: Harvard University Press, 1976, p. 185-196.

RECANATI, François. Direct Reference: from language to thought. Massachusetts: Blackwell, 1997.

RUSSELL, Bertrand. On denoting. Mind, New Series, v.14, n. 56, p. 479-493, 1905.

SALMON, Natan. Reference and essence. Oxford: Princeton University Press, 1982.

SCHIFFER, Stephen. The basis of reference. Erkenntnis, v. 13, p. 171-206, 1978.

SEARLE, John. Proper names. Mind, v. 67, p. 166-173, 1958. 
SOAMES, Scott. Beyond rigidity: the unfinished semantic agenda of naming and necessity. New York: Oxford University Press, 2002.

STRAWSON, Peter. On referring. Mind, New Series, v. 59, n. 235, 1950, p. 320-344.

STANLEY, Jason. Names and rigid designation. In: HALE, Bob; WRIGHT, Crispin (Ed.). A Companion to the Philosophy of Language. Oxford, Basil Blackwell, 1997. p. 555-585. 